\title{
Endovenous Laser Ablation, Radiofrequency Ablation and Flebogrif versus Conventional Surgery in Treatment of Primary Varicose Vein of the Lower Limb: Prospective Randomized Controlled Study
}

Ahmed M. El Mahdi ${ }^{1}$, Sherif Omar El Kerdawi ${ }^{1}$, Ali Mahmoud M. Galal*2

${ }^{1}$ Vascular Surgery Department, Faculty of Medicine, Helwan University, Egypt.

${ }^{2}$ Vascular Surgery Department, Faculty of Medicine, Aswan University, Egypt.

*Corresponding Author: Ali Mahmoud M. Galal, Mobile: (+20)1001816078, E-mail: a_mando76@yahoo.com

\begin{abstract}
Background: Endovenous laser ablation (EVLA), radiofrequency ablation (RFA) and mechanochemical ablation (MOCA) of primary varicose vein are thought to minimise postoperative morbidity and reduce work loss compared with the conventional surgical procedure.

Objective: To determine, whether endovenous ablation methods (radiofrequency, laser and mechanochemical) have any advantages or disadvantages in comparison with conventional surgery, in the treatment of primary varicose vein.

Patients and Methods: This was a prospective randomized study, conducted on forty patients presented at Vascular Outpatient Clinic for management of chronic venous insufficiency. All patients underwent clinical examination and duplex ultrasonography. Ten (10) patients were treated with ligation and stripping of the great saphenous vein (GSV). Ten (10) patients were treated with radiofrequency ablation. Ten (10) patients were treated with endovenous laser ablation. Ten (10) patients were treated with Flebogrif.

Results: Compared with conventional surgery, endovenous ablation methods reduced postoperative discomfort and pain, with a lower complication rate after treatment for avoidance of a groin incision and dissection at the saphenofemoral confluence. Cosmetic demands were also better satisfied. Non-controlled clinical trials have shown that the ablation rate of GSV after EVLA is over 90\%. However, risks of EVLA, RFA and Flebogrif remain in terms of recanalization and neoreflux via junctional tributaries.

Conclusion: RFA, EVLA, and Flebogrif are minimally invasive procedures. Their potential early benefits, by avoiding groin dissection and GSV stripping, have been confirmed by the findings from this trial. Current evidence based on randomized trials consistently demonstrates significant early benefits after RFA, EVLA and Flebogrif in suitable patients with varicose veins.
\end{abstract}

Keywords: Endovenous Laser Ablation, Flebogrif Lower Limb, Radiofrequency Ablation, Varicose Vein.

\section{INTRODUCTION}

Chronic venous disorders encompass a spectrum of venous diseases from simple telangiectasia and reticular veins, varicose veins, leg edema to more severe forms, including hyperpigmented skin changes, dermal sclerosis, and ulcer formation ${ }^{(1)}$.

Chronic venous disorders with manifestations specific to abnormal venous function are termed chronic venous insufficiency (CVI). A distinguishing feature of chronic venous disease (CVD) and (CVI) is that (CVI) indicates more advanced form of chronic venous disorders ${ }^{(2)}$.

Varicose veins have been recognized since the advent of recorded history, and manifestations of CVI, including edema and ulceration, since biblical times. The use of compression therapy dates back to roman times, with foot soldiers using tight wraps to reduce discomfort induced by prolonged standing. Modern understanding of CVI pathophysiology arouse with the work of Brodie and Trendelenburg in the 1850s and 1890s describing superficial and deep venous reflux. Trendelenburg was the first to introduce surgery for varicose veins marking the beginning of modern vascular surgery for this problem ${ }^{(\mathbf{1})}$.
Interventional treatment of superficial venous incompetence can be accomplished by techniques that result in removal, ablation, or ligation of the refluxing venous segment. Current options include high ligation, ligation and stripping, endovascular ablation, sclerotherapy, and phlebotomy ${ }^{(2)}$.

The aim of this study was to determine, whether endovenous ablation methods (radiofrequency, laser and mechanochemical) have any advantages or disadvantages in comparison with conventional surgery, in the treatment of primary varicose vein.

\section{PATIENTS AND METHODS}

This was a prospective randomized study, conducted on forty patients presented at Vascular Outpatient Clinic for management of chronic venous insufficiency. The study was conducted at Ain Shams University Hospitals and Helwan University Hospitals. The study took place from September 2017 to June 2018. All patients underwent clinical examination and duplex ultrasonography.

The patients with saphenofemoral or saphenopopliteal junction incompetence were randomized. Ten (10) patients were treated with ligation and stripping of the GSV. 
Ten (10) patients were treated with radiofrequency ablation. Ten (10) patients were treated with endovenous laser ablation. Ten (10) patients were treated with Flebogrif.

\section{Inclusion Criteria:}

Age between 18 and 70 years, both sexes, clinically visible varicose vein, symptomatic, etiologically primary in superficial and perforator veins, the pathophysiology is reflux and classified by CEAP classification as (C2, S, Ep, As, p, Pr), duplex scan confirmed (saphenofemoral or saphenopopliteal) junction incompetence, and either unilateral or bilateral varicose vein.

Exclusion Criteria: Patients who had previously undergone varicose vein surgical stripping, current deep vein thrombosis or acute superficial vein thrombosis, concomitant peripheral arterial disease (ankle-brachial pressure index of $<0.9$ ), coagulation disorder, pregnancy as they are unable to ambulate, multiple tortuosity of GSV, and duplex confirmed multiple incompetent perforators.

\section{Ethical consent:}

An approval of the study was obtained from Ain Shams and Helwan University Academic and Ethical Committee. Every patient signed an informed written consent for acceptance of the operation and sharing in the study. This work has been carried out in accordance with The Code of Ethics of the World Medical Association (Declaration of Helsinki) for studies involving humans.

All the participating patients were subjected to the following work up:

1- History taking:

A -General history taking: Age, sex, medical history including: hypertension, diabetes, smoking, and for female patient gynecological and obstetric history including number of pregnancies.

B- Vascular history including: History of predisposing factors as occupational prolonged standing, trauma, history of any prior treatment for venous disease including medication, compression therapy, surgery, endovenous, history of superficial thrombophlebitis of DVT, and history of any vascular disease including peripheral arterial disease or coronary artery disease.

\section{2- Examination:}

A- General examination: Pulse, blood pressure, signs of mesenchymal weakness as flat foot.

B-Abdominal examination: Presence of dilated veins crossing inguinal ligament, and abdominal or pelvic swelling
C- Local examination: Inspection, palpation, and percussion: Schwartz's test to detect incompetent valves in superficial system.

3- Investigation:

A- Laboratory investigations: Complete blood picture, coagulation profile, and liver and kidney function test.

$B$-Venous duplex of the lower limb: Preoperative duplex mapping: Duplex scanning is performed to document the patency of the deep veins and to evaluate the extent and severity of the reflux in the superficial venous system (GSV, small saphenous vein and perforators) of patients in the standing position.

\section{4- Procedures:}

A- Stripping procedure: In this group of patients the surgical treatment employed included: flush saphenofemoral ligation, GSV stripping below or above the knee, multiple phlebectomies of the tributaries. All the surgical procedures were performed under general or regional anesthesia.

B-Radiofrequency ablation: In this group of patients, a catheter electrode was used to deliver a high frequency alternating radiofrequency current that leads to venous spasm, collagen shrinkage and physical contraction. The procedure was done either using local infiltration anesthesia or under regional spinal anesthesia.

C- Endovenous laser ablation procedure: In this group of patients, laser energy was delivered through laser fiber to increase blood temperature around the radial firing tip. As a result the endothelium becomes completely destroyed, the collagen in the vessel wall was denatured, and its lumen coagulated. The procedure was done either using local infiltration anesthesia or under regional spinal anesthesia.

D- Flebogrif procedure: In this group of patients, Flebogrif catheter was introduced, simultaneous mechanical damage of inner layer of vein and controlled administration of obliterating agent in form of foam was done. The procedure was done using local anesthesia.

\section{Statistical analysis}

Data were collected, revised, coded and entered to the Statistical Package for the Social Sciences (IBM SPSS) version 23. Data were checked for normality using Kolmogorov-Smirnov test and the quantitative data with parametric distribution were presented as mean, standard deviations and ranges and compared using one-way ANOVA while with nonparametric distribution were presented as median with interquartile range (IQR) and compared using Kruskall-Wallis test. Also the comparison between paired groups with quantitative data and nonparametric distribution were done by using Friedman test followed by post hoc analysis using Wilcoxon Rank test. The p-value was considered significant at the level of $<0.05$. 


\section{RESULTS}

The demographic data, complaints and used anesthesia of the patients are shown in table 1.

Table (1): Demographic data for the procedures

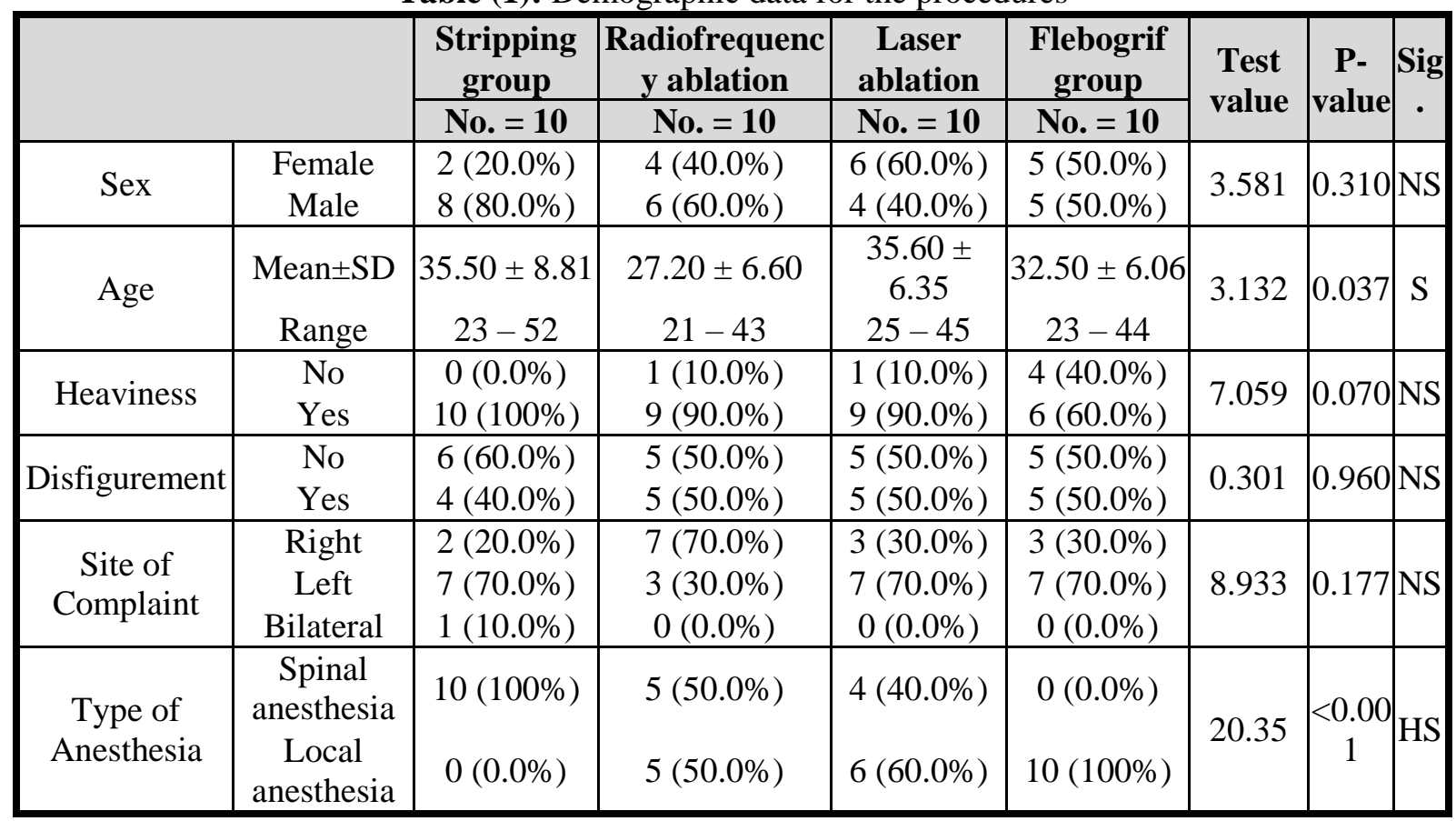

SD: Standard deviation, NS: Non significant, S: Significant, HS: Highly significant (P-value< 0.01)

The rate of ultrasound confirmed recurrence in this trial was slightly higher in the RFA group and Flebogrif group $(10 \%)$ for each group, compared to $0 \%$ in EVLA and stripping groups, which was statistically insignificant (Table 2).

Table (2): Recurrence in stripping, radiofrequency ablation, endovenous laser ablation and Flebogrif groups

\begin{tabular}{|c|c|c|c|c|c|c|c|c|c|c|c|c|}
\hline \multirow{2}{*}{\multicolumn{2}{|c|}{ Dilated veins }} & \multicolumn{2}{|c|}{$\begin{array}{c}\text { Stripping } \\
\text { group }\end{array}$} & \multicolumn{2}{|c|}{$\begin{array}{c}\text { Radiofrequency } \\
\text { ablation }\end{array}$} & \multicolumn{2}{|c|}{$\begin{array}{c}\text { Laser } \\
\text { ablation }\end{array}$} & \multicolumn{2}{|c|}{$\begin{array}{c}\text { Flebogrif } \\
\text { group }\end{array}$} & \multirow{2}{*}{$\begin{array}{l}\text { Test } \\
\text { value }\end{array}$} & \multirow{2}{*}{$\begin{array}{c}P \text { - } \\
\text { value }\end{array}$} & \multirow{2}{*}{ Sig } \\
\hline & & No. & $\%$ & No. & $\%$ & No. & $\%$ & No. & $\%$ & & & \\
\hline \multirow{2}{*}{$\begin{array}{c}\text { Before } \\
\text { procedure }\end{array}$} & No & 0 & $0.0 \%$ & 0 & $0.0 \%$ & 0 & $0.0 \%$ & 0 & $0.0 \%$ & \multirow{2}{*}{0} & \multirow{2}{*}{1} & \multirow{2}{*}{ NS } \\
\hline & Yes & 10 & $100.0 \%$ & 10 & $100.0 \%$ & 10 & $100.0 \%$ & 10 & $100.0 \%$ & & & \\
\hline \multirow{2}{*}{1 week } & No & 10 & $100.0 \%$ & 10 & $100.0 \%$ & 10 & $100.0 \%$ & 9 & $90.0 \%$ & \multirow{2}{*}{3.077} & \multirow{2}{*}{0.380} & \multirow{2}{*}{ NS } \\
\hline & Yes & 0 & $0.0 \%$ & 0 & $0.0 \%$ & 0 & $0.0 \%$ & 1 & $10.0 \%$ & & & \\
\hline \multirow{2}{*}{1 month } & No & 10 & $100.0 \%$ & 10 & $100.0 \%$ & 10 & $100.0 \%$ & 9 & $90.0 \%$ & \multirow{2}{*}{3.077} & \multirow{2}{*}{0.380} & \multirow{2}{*}{ NS } \\
\hline & Yes & 0 & $0.0 \%$ & 0 & $0.0 \%$ & 0 & $0.0 \%$ & 1 & $10.0 \%$ & & & \\
\hline \multirow{2}{*}{3 month } & No & 10 & $100.0 \%$ & 9 & $90.0 \%$ & 10 & $100.0 \%$ & 9 & $90.0 \%$ & \multirow{2}{*}{2.105} & \multirow{2}{*}{0.551} & \multirow{2}{*}{ NS } \\
\hline & Yes & 0 & $0.0 \%$ & 1 & $10.0 \%$ & 0 & $0.0 \%$ & 1 & $10.0 \%$ & & & \\
\hline
\end{tabular}

NS: Non significant

Recurrence was associated with $2^{\text {nd }}$ and $4^{\text {th }}$ groups, infection and ecchymosis associated with $1^{\text {st }}$ group, superficial thrombophlebitis was associated with $2^{\text {nd }}, 3^{\text {rd }}$ and $4^{\text {th }}$ groups, DVT was associated with $4^{\text {th }}$ group but all these associations were not significantly different (Table 3). 
Table (3): Postoperative complications in conventional surgery, radiofrequency ablation, endovenous laser ablation and Flebogrif

\begin{tabular}{|c|c|c|c|c|c|c|c|c|c|c|c|}
\hline & \multicolumn{2}{|c|}{$\begin{array}{c}\text { Stripping } \\
\text { group }\end{array}$} & \multicolumn{2}{|c|}{$\begin{array}{c}\text { Radiofrequen } \\
\text { cy ablation }\end{array}$} & \multicolumn{2}{c|}{$\begin{array}{c}\text { Laser } \\
\text { ablation }\end{array}$} & \multicolumn{2}{c|}{$\begin{array}{c}\text { Flebogrif } \\
\text { group }\end{array}$} & $\begin{array}{c}\text { Test } \\
\text { value }\end{array}$ & $\begin{array}{c}\text { P- } \\
\text { value }\end{array}$ & Sig. \\
\cline { 2 - 13 } & No. & $\%$ & No. & $\%$ & No. & $\%$ & No. & $\%$ & & \\
\hline Recurrence & 0 & $0.0 \%$ & 1 & $10.0 \%$ & 0 & $0.0 \%$ & 1 & $10.0 \%$ & 2.105 & 0.551 & NS \\
\hline Infection & 1 & $10.0 \%$ & 0 & $0.0 \%$ & 0 & $0.0 \%$ & 0 & $0.0 \%$ & 3.077 & 0.380 & NS \\
\hline Ecchymosis & 4 & $40.0 \%$ & 0 & $0.0 \%$ & 2 & $20.0 \%$ & 0 & $0.0 \%$ & 8.627 & 0.035 & S \\
\hline Parenthesis & 2 & $20.0 \%$ & 1 & $10.0 \%$ & 2 & $20.0 \%$ & 0 & $0.0 \%$ & 2.514 & 0.473 & NS \\
\hline $\begin{array}{c}\text { Superficial } \\
\text { thrombophlebitis }\end{array}$ & 0 & $0.0 \%$ & 1 & $10.0 \%$ & 1 & $10.0 \%$ & 1 & $10.0 \%$ & 1.081 & 0.782 & NS \\
\hline $\begin{array}{c}\text { Deep venous } \\
\text { thrombosis }\end{array}$ & 0 & $0.0 \%$ & 0 & $0.0 \%$ & 0 & $0.0 \%$ & 1 & $10.0 \%$ & 3.077 & 0.380 & NS \\
\hline Hyperpigmentation & 0 & $0.0 \%$ & 0 & $0.0 \%$ & 0 & $0.0 \%$ & 0 & $0.0 \%$ & 0 & 1 & NS \\
\hline
\end{tabular}

NS: Non significant, S: Significant, HS: Highly significant (P-value $<0.01)$

Regarding the pain evaluation, our study showed no significant difference among all groups. However there was significant decrease in pain score in each group (Table 4).

Table (4): Statistical difference between median values in pain score between great saphenous vein stripping, radiofrequency ablation, endovenous laser ablation and Flebogrif before and after the procedure at 1 week, 1 month and 3 months

\begin{tabular}{|c|c|c|c|c|c|c|c|c|}
\hline \multirow{2}{*}{\multicolumn{2}{|c|}{ Pain Score (VAS) }} & $\begin{array}{l}\text { Stripping } \\
\text { group }\end{array}$ & $\begin{array}{c}\text { Radiofrequency } \\
\text { ablation }\end{array}$ & $\begin{array}{c}\text { Laser } \\
\text { ablation }\end{array}$ & $\begin{array}{l}\text { Flebogrif } \\
\text { group }\end{array}$ & \multirow{2}{*}{$\begin{array}{c}\text { Test } \\
\text { value• }\end{array}$} & \multirow{2}{*}{$\begin{array}{c}P- \\
\text { value }\end{array}$} & \multirow[t]{2}{*}{ Sig. } \\
\hline & & No. $=\mathbf{1 0}$ & No. $=10$ & No. $=10$ & No. $=10$ & & & \\
\hline $\begin{array}{l}\text { Before } \\
\text { Procedure }\end{array}$ & $\begin{array}{c}\text { Median } \\
\text { (IQR) } \\
\text { Range }\end{array}$ & $\begin{array}{c}8.5(8-9) \\
7-9\end{array}$ & $\begin{array}{c}7.5(7-8) \\
5-9\end{array}$ & $\begin{array}{c}7(6-7) \\
5-8\end{array}$ & $\begin{array}{c}7.5(5-8) \\
5-9\end{array}$ & 10.716 & 0.013 & $S$ \\
\hline 1 Week & $\begin{array}{c}\text { Median } \\
(\mathrm{IQR}) \\
\text { Range }\end{array}$ & $\begin{array}{c}6(6-7) \\
5-7\end{array}$ & $\begin{array}{c}4(4-5) \\
3-6\end{array}$ & $\begin{array}{c}4.5(4-5) \\
3-6\end{array}$ & $\begin{array}{c}5.5(4-7) \\
3-7\end{array}$ & 14.161 & 0.003 & HS \\
\hline 1 month & $\begin{array}{c}\text { Median } \\
\text { (IQR) } \\
\text { Range }\end{array}$ & $\begin{array}{c}2(2-3) \\
1-3\end{array}$ & $\begin{array}{c}2(2-3) \\
0-3\end{array}$ & $\begin{array}{c}2(2-3) \\
0-3\end{array}$ & $\begin{array}{c}3(2-3) \\
2-4\end{array}$ & 3.895 & 0.273 & NS \\
\hline 3 months & $\begin{array}{c}\text { Median } \\
\text { (IQR) } \\
\text { Range }\end{array}$ & $\begin{array}{c}0.5(0-2) \\
0-3\end{array}$ & $\begin{array}{c}1(0-2) \\
0-5\end{array}$ & $\begin{array}{c}1.5(0-2) \\
0-2\end{array}$ & $\begin{array}{c}1(0-1) \\
0-2\end{array}$ & 0.893 & 0.827 & NS \\
\hline \multicolumn{2}{|c|}{ Friedman test value } & 28.653 & 25.719 & 29.250 & 30.000 & & & \\
\hline \multicolumn{2}{|c|}{ P-value } & $<0.001$ & $<0.001$ & $<0.001$ & $<0.001$ & & & \\
\hline \multicolumn{9}{|c|}{ Post Hoc analysis by Wilcoxon Rank test } \\
\hline \multicolumn{2}{|c|}{ Pre Vs 1 week } & 0.004 & 0.005 & 0.004 & 0.004 & & & \\
\hline \multicolumn{2}{|c|}{ Pre Vs 1 month } & 0.005 & 0.004 & 0.005 & 0.005 & & & \\
\hline \multicolumn{2}{|c|}{ Pre Vs 3 month } & 0.005 & 0.005 & 0.005 & 0.005 & & & \\
\hline
\end{tabular}

IQR: Interquartile range, NS: Non significant, S: Significant, HS: Highly significant (P-value< 0.01$)$

There was significant decrease in pain score in each group (Fig. 1). 


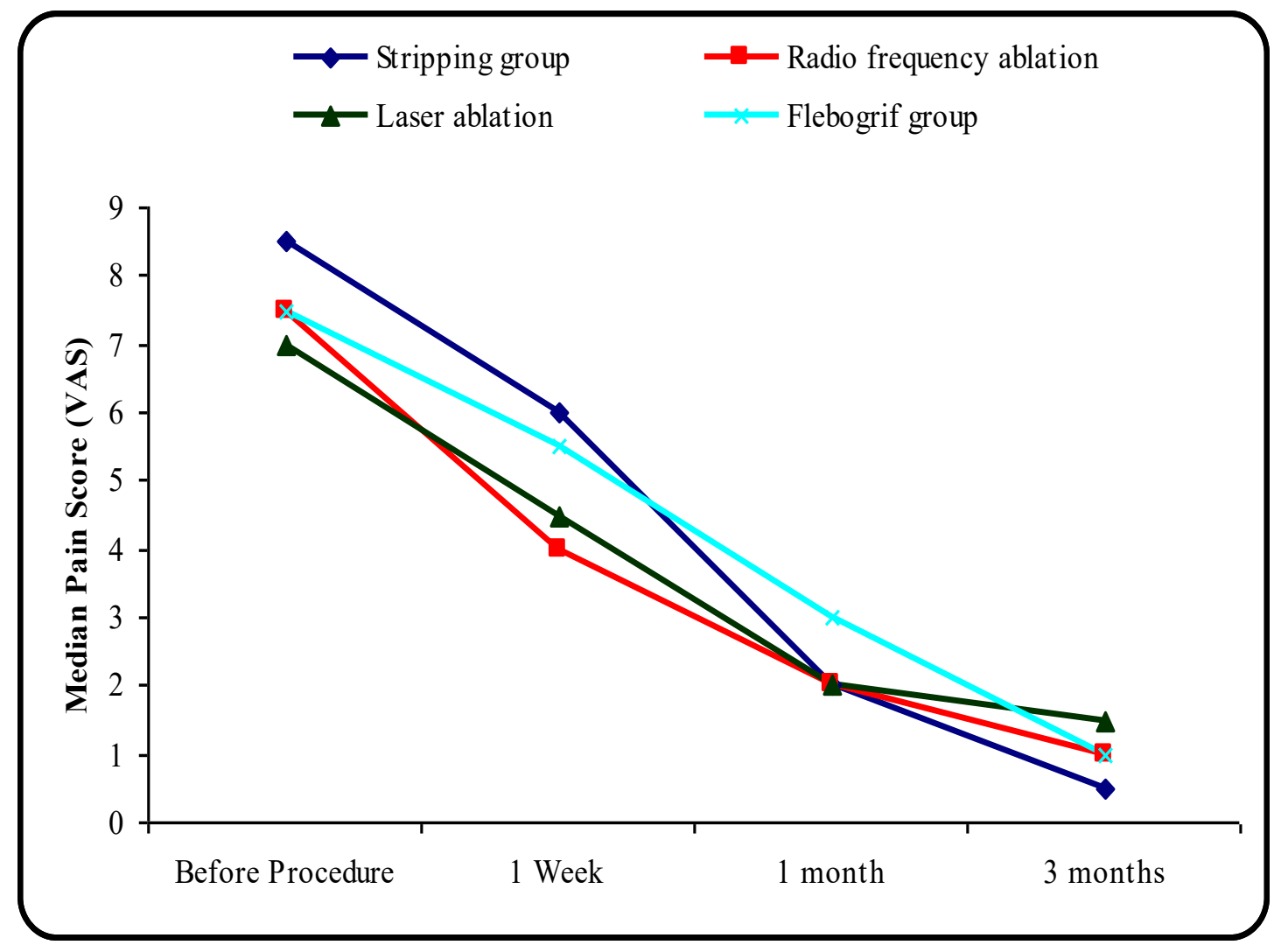

Figure (1): Statistical difference between median pain score between great saphenous vein stripping, radiofrequency ablation, endovenous laser ablation and Flebogrif before and after the procedure at 1 week, 1 month and 3 months

Regarding subjective assessment that was undertaken by the patients, our study showed no statistical difference between the four groups after 3 months follow up. This showed that most patients had scored the outcome of their treatment as class A or B i.e. between excellent and good for most of the procedures (Table 5).

Table (5): Statistical difference in subjective scoring between conventional surgery, radiofrequency ablation, endovenous laser ablation and Flebogrif at 1 week, 1 month, and 3 months

\begin{tabular}{|c|c|c|c|c|c|c|c|c|}
\hline \multirow{2}{*}{\multicolumn{2}{|c|}{$\begin{array}{l}\text { Subjective Clinical Ex. } \\
\text { Score }\end{array}$}} & \multirow{3}{*}{$\begin{array}{c}\begin{array}{c}\text { Stripping } \\
\text { group }\end{array} \\
\text { No. = 10 } \\
1(1-2) \\
1-2 \\
\end{array}$} & \multirow{3}{*}{$\begin{array}{c}\begin{array}{c}\text { Radiofrequency } \\
\text { ablation }\end{array} \\
\text { No. }=\mathbf{1 0} \\
1(1-2) \\
1-2 \\
\end{array}$} & \multirow{3}{*}{$\begin{array}{c}\begin{array}{c}\text { Laser } \\
\text { ablation }\end{array} \\
\text { No. = 10 } \\
1(1-2) \\
1-2 \\
\end{array}$} & \multirow{3}{*}{$\begin{array}{c}\begin{array}{c}\text { Flebogrif } \\
\text { group }\end{array} \\
\text { No. }=\mathbf{1 0} \\
2(1-2) \\
1-3 \\
\end{array}$} & \multirow{3}{*}{$\begin{array}{c}\begin{array}{c}\text { Test } \\
\text { value }\end{array} \\
0.576\end{array}$} & \multirow{3}{*}{$\begin{array}{c}\begin{array}{c}\text { P- } \\
\text { value }\end{array} \\
0.902\end{array}$} & \multirow{3}{*}{$\begin{array}{l}\text { Sig. } \\
\text { NS }\end{array}$} \\
\hline & & & & & & & & \\
\hline 1 week & $\begin{array}{c}\text { Median (IQR) } \\
\text { Range }\end{array}$ & & & & & & & \\
\hline 1 month & $\begin{array}{c}\text { Median (IQR) } \\
\text { Range }\end{array}$ & $\begin{array}{c}1(1-1) \\
1-2\end{array}$ & $\begin{array}{c}1(1-2) \\
1-2\end{array}$ & $\begin{array}{c}1(1-2) \\
1-2\end{array}$ & $\begin{array}{c}1(1-2) \\
1-3\end{array}$ & 1.393 & 0.707 & NS \\
\hline 3 month & $\begin{array}{c}\text { Median (IQR) } \\
\text { Range }\end{array}$ & $\begin{array}{c}1(1-1) \\
1-2\end{array}$ & $\begin{array}{c}1(1-2) \\
1-4\end{array}$ & $\begin{array}{c}1(1-2) \\
1-2\end{array}$ & $\begin{array}{c}1(1-2) \\
1-3\end{array}$ & 2.456 & 0.483 & NS \\
\hline Friedm & nan test value & 4.667 & 0.500 & 0.667 & 0.667 & & & \\
\hline & P-value & 0.097 & 0.779 & 0.717 & 0.717 & & & \\
\hline & & Post H & c analysis by Wil & xon Rank & & & & \\
\hline 1 week & K Vs 1 month & 0.157 & 0.317 & 1.000 & 0.317 & & & \\
\hline 1 week & K Vs 1 month & 0.083 & 0.705 & 0.564 & 0.564 & & & \\
\hline 1 mont & h Vs 3 month & 0.317 & 0.414 & 0.564 & 1.000 & & & \\
\hline
\end{tabular}

IQR: Interquartile range, NS: Non significant 


\section{DISCUSSION}

Endovenous ablation procedures have replaced ligation and stripping as the technique for elimination of saphenous vein reflux. Endovenous procedures are far less invasive than surgery and have lower complication rate. The procedure is well tolerated by patients, and it produces good cosmetic results ${ }^{(3)}$.

The present study compares between the radiofrequency ablation (RFA), endovenous laser ablation (EVLA), Flebogrif and the conventional surgical technique. The radiofrequency ablation group had significantly younger age, however there was no significant difference among the groups as regard sex. In a study conducted by Venermo et al. ${ }^{(4)}$, there were 214 patients: 65 of them had surgery and 73 had EVLA. In a study conducted by Hammad et al. ${ }^{(5)}$, there were 100 patients: 50 had surgery, 50 had RFA and there was non-significant difference in age and sex between both groups.

All patients in this trial were primary symptomatic uncomplicated varicose veins (CEAP clinical class C2), which was the same as other studies conducted by Venermo et al. ${ }^{(4)}$. Regarding the patients' complaint, $90 \%$ of the radiofrequency group came complaining of heaviness and $50 \%$ complaining of disfigurement, in EVLA group 90\% came complaining of heaviness and $50 \%$ complaining of disfigurement, in Flebogrif group 60\%came complaining of heaviness and 50\% complaining of disfigurement, while in the stripping group, $100 \%$ came complaining of heaviness and $40 \%$ complaining of disfigurement.

Regarding the pain assessment, our study showed no significant difference among all groups. A randomized controlled study published by Venermo et al. ${ }^{(4)}$ comparing the EVLA versus stripping for 1 year follow up period showed that pain values improved significantly in comparison with preoperative values in all groups, with no significant differences between them. Perioperative pain was significantly reduced shorter after EVLA (8 days) than surgery (12 days). In the study conducted by Hammad $\boldsymbol{e t}$ al. ${ }^{(5)}$, there was high significant difference in the postoperative scores of pain in comparison with preoperative scores in both RFA group and surgical group.

In the current trial, RFA and EVLA took significantly longer time to be performed than conventional surgery and Flebogrif. This was due to tumescent infiltration and detailed duplex scanning before and after treatment. RFA and EVLA involved considerably less tissue dissection and trauma. Patients who underwent RFA, EVLA and Flebogrif returned to work at least one week earlier than those who had conventional surgery. In Venermo et al. ${ }^{(4)}$, the mean duration of treatment was 95 (range 62-155) $\mathrm{min}$ in the surgery group and 83 (range 50-139) $\mathrm{min}$ in the EVLA group $(\mathrm{P}<0 \cdot 001)$. In the study conducted by Hammad et al. (5), RFA took longer time than conventional surgery. In RFA group there was decrease in hospital stay due to the use of tumescent anesthesia, the early ambulation of the patients, less postoperative pain, the minimal need for analgesics.

Regarding subjective assessment that was undertaken by the patients, our study showed no statistical difference between the four groups after 3 months follow up. This showed that most patients had scored the outcome of their treatment as class A or B i.e. between excellent and good for most of the procedures.

The rate of ultrasound confirmed recurrence in this trial was slightly higher in the RFA group and Flebogrif group (10\%) for each group, compared to $0 \%$ in EVLA and stripping groups, which was statistically insignificant. A study conducted by Venermo et al. ${ }^{(4)}$ considered one year follow up may be too early to show the consequences of recurrent reflux and in a study conducted by Hammad et al. ${ }^{(5)}$, the frequency of recurrent varicose veins was not significantly different between the surgery and RFA groups, about 10 percent of patients of each group developed varices.

Ciostek and his colleagues ${ }^{(6)}$ agreed with the results of the current study regarding Flebogrif efficacy. Their study was performed in the years 20112013, and it evaluated 40 patients with varicose veins. Efficacy of the procedure, defined as closure of the treated vein, and clinical result evaluated using the Venous Clinical Severity Score (VCSS) were assessed after 1, 3, 6 and 12 months. Efficacy of the procedure after $1,3,6$ and 12 months was $97.4 \%, 94.9 \%, 89.7 \%$ and $89.7 \%$, respectively. Statistical analysis of the VCSS before the procedure and after 12 months revealed statistically significant improvements regarding pain, presence of varicose veins, edema, number and size of active ulcers, their duration, size of active ulcers and the use of compression therapy.

Also, Zubilewicz and his colleagues (7) agreed with the results of the current study regarding Flebogrif efficacy. Their study was performed on 200 patients, including 170 women and 30 men treated with ablation with Flebogrif TM to treat varicose veins. All patients were qualified based on the ultrasound in a standing position confirming incompetence of the great saphenous vein or small saphenous vein. The procedure was highly effective reaching $96 \%$ at 3 months of follow-up, provides good cosmetic effect and the low rate of complications. Minimal invasiveness of mechanochemical ablation with Flebogrif ${ }^{\mathrm{TM}}$ may improve the quality of life during the postoperative period ${ }^{(7)}$.

In this executed trial, the rate of complications was as the following: 1 case (10\%) recorded postoperative wound infection in the stripping group, which was improved on medical treatment and repeated dressing and 4 cases $(40 \%)$ recorded ecchymosis and 2 cases (20\%) recorded paresthesia all of them improved among the first month whereas the RFA group showed 1 case (10\%) of recurrence and 1 
case $(10 \%)$ of superficial thrombophlebitis and 1 case (10\%) of paresthesia. Regarding EVLA group 2 cases (20\%) recorded ecchymosis, 2 cases $(20 \%)$ recorded paresthesia and 1 case (10\%) recorded superficial thrombophlebitis. Regarding Flebogrif group 1 case $(10 \%)$ showed recurrence, $1 \quad(10 \%)$ case was complicated by superficial thrombophlebitis and 1 (10\%) case was complicated by deep venous thrombosis. There were no cases recorded with skin burns.

In Venermo et al. ${ }^{(4)}$, there were no major complications related to the procedures. Three patients $(4 \%)$ in the EVLA group and three $(5 \%)$ in the surgery group had a superficial wound infection. All resolved with oral antibiotics; none of the patients needed treatment in hospital. At the 1-month follow up, $(62 \%)$ of patients in the surgery group had a hematoma (defined as visible localized aggregate of extravasated blood) in the operated leg, compared with $(42 \%)$ in the EVLA group. Skin pigmentation was after surgery and EVLA (5\% and 4\% respectively. Paraesthesia was rare in surgery and EVLA groups (2\% and $3 \%$ respectively). In Hammad et al. ${ }^{(5)}$, there were no significant hematomas; defined as a three dimensional ultrasound-detectable interstitial clot, occurred in the (RFA) group in the contrary to the (surgery) group. As regard to phlebitis; it was encountered in $(8 \%)$. There was $(2 \%)$ of deep vein thrombosis (DVT) in the post tibial vein which improved with full anticoagulation. Skin burn occurred in the (RFA) group was in the form of mild erythema in $(14 \%)$ of the cases and in $(2 \%) 2^{\text {nd }}$ degree burn, which might be due to insufficient tumescent anesthesia and very superficial veins. All cases improved with conservative management. The key to avoid and decrease incidence of skin burns and pigmentation is the very generous use of tumescent fluid under distinctness, uniformity and stability (DUS) guidance and making sure that at least $1 \mathrm{~cm}$ of fluid is surrounding the treated vein all around. In the (RFA) group there was skin hyperpigmentation in (8\%); (6 \%) improved over 3-4 months and (2\%) persisted. In the (RFA) group nerve damage (paraesthesia) occurred in (8\%) along the supply of the saphenous nerve due to ablation of the lower part of GSV, RFA of the distal GSV should be abandoned, all of them improved, and after 6 months there were no residual paraesthesia.

Regional anesthesia was the main type of anesthesia used in this study however RFA, EVLA and Flebogrif procedures have the advantage of using local anesthesia with early postoperative recovery and discharge from hospital.

The European Society for Vascular Surgery (ESVS) guidelines ${ }^{(8)}$ and the National Institute for Health and Care Excellence (NICE) guidelines (9) recommended endovenous thermal ablation in preference to open surgery. Long-term follow-up data for endovenous thermal ablation are still lacking; current recommendations are largely based on relatively short-term (one- to two-year) clinical outcomes. A new generation of devices for endovenous ablation of truncal veins has been emerging in recent years. The new devices such as glue and mechanochemical ablation aim to avoid the use of heat as energy source and associated requirement for tumescence around the vein ${ }^{(\mathbf{1 0})}$.

\section{CONCLUSION}

RFA, EVLA, and Flebogrif are minimally invasive procedures. Their potential early benefits, by avoiding groin dissection and GSV stripping, have been confirmed by the findings from this trial. Current evidence based on randomized trials consistently demonstrates significant early benefits after RFA, EVLA and Flebogrif in suitable patients with varicose veins.

\section{Financial support and sponsorship: Nil. Conflict of interest: Nil.}

\section{REFERENCES}

1. Santler $B$ and Goerge $T$ (2017): Chronic venous insufficiency - a review of pathophysiology, diagnosis, and treatment. Journal Der Deutschen Dermatologischen Gesellschaft., 15(5): 538-556.

2. Aleksiejew-Kleszczyński T, Jagielska-Chwała M (2015): Varicose veins of lower extremities, hemodynamics and treatment methods. Advances in Clinical and Experimental Medicine, 24(1): 5-14.

3. Proebstle T, Van den Bos R (2017): Endovenous ablation of refluxing saphenous and perforating veins. Vasa., 46 (3): 159166.

4. Venermo M, Saarinen J, Eskelinen E et al. (2016): Randomized clinical trial comparing surgery, endovenous laser ablation and ultrasound-guided foam sclerotherapy for the treatment of great saphenous varicose veins. British Journal of Surgery, 103(11): 1438-44.

5. Hammad A, Abd el Modaber A, Aliyev V (2018): Conventional surgery versus endovenous radiofrequency ablation in management of patients with primary varicose veins. Vascular Diseases and Therapeutics, 3(1):1-11.

6. Ciostek P, Kowalski M, Woźniak W et al. (2015): Phlebogriffe- a new device for mechanochemical ablation of incompetent saphenous veins: a pilot study. Phlebological Review, 23(3): 72-7.

7. Zubilewicz T, Terlecki P, Terlecki K et al. (2016): Application of endovenous mechanochemical ablation (MOCA) with Flebogrif ${ }^{\mathrm{TM}}$ to treat varicose veins of the lower extremities: a single center experience over 3 months of observation. Acta Angiologica, 22(4): 137-42.

8. Wittens C, Davies A, Bækgaard $\mathrm{N}$ et al. (2015): Management of chronic venous disease: Clinical practice guidelines of the European Society for Vascular Surgery (ESVS). Eur J Vasc Endovasc Surg., 49(6):678-737.

9. National Institute for Health and Care Excellence (NICE) guidelines (2013): The guidelines manual. https://www.nice.org.uk/process/pmg6/resources/theguidelines-manual-pdf-2007970804933

10. Guo B, Tjosvold $L$ (2016): Endovenous thermal ablation interventions for symptomatic varicose veins of the legs-An update. Institute of Health Economics (IHE). https://www.ncbi.nlm.nih.gov/books/NBK493556/ 